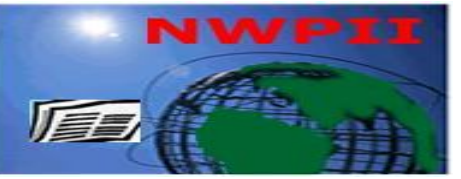

American Journal of Biomedical Sciences

ISSN: 1937-9080

nwpii.com/ajbms

\title{
Agglutination of Human Spermatozoa Due to Human Semen Culture Bacterial Isolates Bearing Sperm Ligand
}

\author{
Vijay Prabha, Neha Thakur, Siftjit Kaur, Navchetan Kaur, Arvind Singh and Sushila Kala
}

Department of Microbiology, Panjab University, Chandigarh- 160014, India.

*Corresponding Author

Dr. Vijay Prabha

Department of Microbiology

Panjab University

Chandigarh -160014, India

Tel: 91-0172- 2534144

Fax: 91- 0172-2541770

E mail: satishvijay11@yahoo.com

Received: 1 December 2008; | Revised: 2 February 2009; | Accepted: 6 February 2009

\begin{abstract}
Sperm ligand on Escherichia coli that agglutinates human spermatozoa has been extracted from washed E. coli cells by incubating with $3 \mathrm{M} \mathrm{NaCl}$ for $12 \mathrm{~h}$ at $37^{\circ} \mathrm{C}$ under shake conditions (150 rpm). Further the sperm ligand was purified after extensive dialysis against double distilled water by step down chromatography procedures (molecular weight sieving, anion exchange). The purification procedure yielded a protein of apparent homogeneity. The ligand was heat labile as it could not withstand a temperature of $60^{\circ} \mathrm{C}$ for 10 minutes. The ligand did not pass through the dialysis tubing. The molecular weight was found to be $\sim 71 \mathrm{KDa}$. Electron microscopy studies of washed sperm cells treated with purified ligand showed profound morphological alterations to head, neck and tail.
\end{abstract}

Keywords: E. coli; ligand; spermatozoa; agglutination; scanning electron microscopy

\subsection{Introduction}

For successful fertilization, motility is the most obvious and most essential sperm function and has been repeatedly shown to be predictive of fertilization in vitro (Bonde et al., 1998). Several studies have shown that the motility characteristics of spermatozoa are of the utmost importance for the men's fertility (Karpuz et al., 2007). Spermatozoa dysfunction is the single most important cause of infertility. A decrease in spermatozoa motility with time is universal phenomenon. This reduction differs from species to species and also among individuals of the same species, as in the human male. Most investigators agree that the majority of spermatozoa cease to move within the first 24 hours. The survival of spermatozoa after ejaculation is dependant on the environmental conditions under which they are kept. In the female genital tract they may remain 
active for several days (Hafez, 1980), but their activity is of much shorter duration if they remain in the seminal fluid outside the body.

Male genital infections are relevant cause in the etiology of infertility due to abnormalities in sperm quality (Golshani et al., 2006; Pellati et al., 2008), affecting spermatozoal count and motility. The comparison of semen characteristics between infected and non-infected men show that motile spermatozoa and viability are lower when the microorganisms are present in the semen (Menkveld et al., 2001). It appears that bacteria have a direct effect on semen quality with negative consequences in fertility.

Men may have infections of their reproductive tract, these may include infection of the prostate (prostatitis), of the epididymus (epididymitis), or of the testis (orchitis). The principal microorganism causing prostatitis and epididymitis is E. coli (Giamarellou et al., 1984). The significance of asymptomatic infection or bacterial colonization of the male genital tract is less well-known and the interpretation of semen cultures in a fertility clinic is puzzling.

E. coli is one of the most frequent microorganism isolated from the ejaculate (Huerta et al., 2002). Several reports describe sperm agglutination and immobilization by $E$. coli (Huwe et al., 1998; Khalili \& Sharifi-Yazdi, 2001). Paulson \& Polakoski (1977) investigated the mechanism of how $E$. coli immobilizes spermatozoa and they reported a factor, apparently excreted by the bacteria which immobilizes spermatozoa without agglutinating it. However, Diemer et al. (1996) reported that E. coli inhibits sperm motility by directly adhering to and agglutinating spermatozoa. Rapidity and extent of sperm-E. coli agglutination indicated strong adhesive forces. Bartoov et al. (1991) proposed that mannose plays a critical role in adherence of E. coli to sperm. E. coli adherence is mediated by mannose residues present on the sperm. But what are the ligands? The purpose of this study is to investigate about the human sperm ligand on $E$. coli that binds to mannose present on the sperm.

\subsection{Materials and Methods}

\section{Sperm Samples}

Spermatozoa were obtained from healthy donors and men undergoing evaluation of fertility at PGIMER, Chandigarh, India, by masturbation following a $24 \mathrm{~h}$ continence period. Only ejaculates showing sperm parameters according to World Health Organization criteria (1999) were used. Depending upon the experiment, ejaculates were used unwashed or were washed twice with PBS (50mM, pH 7.2) and suspended in PBS. The number of sperm was checked by counting in a hemocytometer and was adjusted to $40 \times 10^{6}$ spermatozoa $\mathrm{ml}^{-1}$.

\section{Bacterial Samples}

Semen samples of 10 males attending to infertility clinic (General Hospital, Sector-16, Chandigarh) were collected in the clinic by masturbation following a $24 \mathrm{~h}$ continence period. Before taking the semen samples the patient's recent medical history was taken into consideration. The semen samples were taken only from only those males who were without clinical symptoms of urogenital infections and who had not had antibiotic intake for atleast a week. All the patients were of the age group of 20-40 years. Samples were collected in sterile wide mouth plastic container. Samples underwent liquefaction at room temperature for 30 minutes. Then the samples were streaked on Blood agar plates separately and the plates were incubated aerobically at $37^{\circ} \mathrm{C}$ for $24-48 \mathrm{~h}$. The isolates were identified according to Bergey's Manual of Determinative Bacteriology (1994). The most abundant microorganism was Staphylococcus while E. coli could be isolated from only two males. Screening of both the $E$. coli isolates for interaction with human sperm identified both of them as an inducer of sperm agglutination. The isolate (No. 2) giving maximum agglutination was selected for further studies.

\section{Sperm Bacteria Interaction}

The isolate giving maximum agglutination (Isolate No. 2) was grown in Luria Broth (LB) under shake conditions (150 rpm) at $37^{\circ} \mathrm{C}$ for $48 \mathrm{~h}$. The culture was centrifuged at $10,000 \mathrm{~g}$ for 10 minutes at $4^{\circ} \mathrm{C}$. Cell free supernatant was prepared by passing the supernatant through a $0.22 \mu \mathrm{m}$ 
Millipore filter. The bacterial cells were washed twice with sterile PBS (50mM, pH 7.2). Equal volumes of semen samples $\left(40 \times 10^{6}\right.$ spermatozoa $\left.\mathrm{ml}^{-1}\right)$ and bacterial cell culture $\left(10^{7}\right.$ cells $\mathrm{ml}^{-}$ $\left.{ }^{1}\right) /$ washed cells/cell free supernatant were mixed and incubated at $37^{\circ} \mathrm{C}$ for $2 \mathrm{~h}$. One drop of each was placed on a glass slide covered with a coverslip and observed for agglutination at $400 \mathrm{X}$ magnification under light microscope (Getner, Ambala, India). As a control, a sterile growth medium was used. As only cell culture and washed cells were able to agglutinate the spermatozoa, whereas culture supernatant failed to do so, therefore, further studies were carried out with washed cells. Pretreatment of E. coli by sonication produced bacterial fragments that were still able to agglutinate spermatozoa. The centrifugation of $E$. coli fragments at $10,000 \mathrm{~g}$ for 5minutes completely removed spermagglutinating elements from the solution.

\section{Extraction of Sperm ligand}

Extraction of sperm ligand from washed $E$. coli cells (48 h old) was done by salt washing method. The washed cells of $E$. coli $(1000 \mathrm{ml}, 48 \mathrm{~h}$ old cell culture) were incubated with 1, 2, 3, 4 and $5 \mathrm{M}$ solution of $\mathrm{NaCl}$ under shake conditions (150 $\mathrm{rpm})$ at $37^{\circ} \mathrm{C}$ for different time intervals $2,4,8,12$ and $24 \mathrm{~h}$, separately. Then the cells were centrifuged at $10,000 \mathrm{~g}$ for 30 minutes. The resulting cell pellet and supernatant (which was dialyzed against double distilled water overnight at $4^{\circ} \mathrm{C}$ and passed through the UM05 Amicon filter) were analyzed for sperm ligand. As pellet did not show any spermatozoal agglutinating activity, further work was carried out with the supernatant.

The washed cells of $E$. coli were also subjected to sonication. $1000 \mathrm{ml}$ of $48 \mathrm{~h}$ old cell culture of E. coli was centrifuged at $8000 \mathrm{~g}$ for 15 min and the cells collected were sonicated (B.Braun, Labsonic 2000 Ltd.) for $10 \mathrm{~min}$ and then centrifuged at $10,000 \mathrm{~g}$ for $30-45 \mathrm{~min}$. Both the cell debris and the sonicated supernatant were checked for agglutination activity. The sperm agglutinating activity was absent in sonicated supernatant. Further the cell debris was treated with different molarities of $\mathrm{NaCl}$ solution at $37^{\circ} \mathrm{C}$ for different time intervals as done with washed cells. The solution was then centrifuged at 10,000 $\mathrm{g}$ and both cell debris and dialyzed supernatant were checked for the agglutination of spermatozoa. The agglutinating activity was absent in the cell debris so the further study was done with the dialyzed supernatant. Amongst the two methods of extraction described above, salt washing was found to be more efficient in extracting the sperm ligand from washed $E$. coli cells then sonicated cells (each prepared from $1000 \mathrm{ml}$ of $48 \mathrm{~h}$ old cell culture). Therefore,this was used as a method of choice for extraction of sperm ligand on E. coli. Boiling of supernatant for $10 \mathrm{~min}$ waived its spermatozoal agglutinating activity indicating that the active component may be a protein.

\section{Purification of Sperm ligand}

Purification of crude sperm ligand consists of filtration of dialyzed and concentrated fraction extracted with $3 \mathrm{M} \mathrm{NaCl}$ (Qualigens Fine Chemicals, India) through a Sephadex G-200 (Pharmacia Fine Chemicals, Uppsala) column. Fractions of $3 \mathrm{ml}$ each were collected and were read at $280 \mathrm{~nm}$ UV spectrophotometer. Fractions showing agglutinating activity were pooled and concentrated using PEG 6000 under cold conditions.

The fractions concentrated after molecular sieving through G-200 were applied to DEAE cellulose (Hi-Media laboratories, Mumbai, India) column. Final elution was done with 0.05, 0.1, 0.2, 0.4 and $0.6 \mathrm{M} \mathrm{NaCl}$ dissolved in PBS $(50 \mathrm{mM}, \mathrm{pH}$ 7.2). Fractions of $4 \mathrm{ml}$ each were collected and read at 280nm on UV spectrophotometer (Hitachi U-2900). Fractions showing agglutinating activity were pooled and concentrated. Polyacrylamide gel electrophoresis (PAGE) of purified sperm ligand was carried out to check the purification status. Molecular weight was estimated by sodium dodecyl sulphate- polyacrylamide gel electrophoresis (SDS-PAGE) using the standard molecular weight markers.

\section{Scanning Electron Microscopy (SEM)}

SEM on a Jeol Scanning Microscope (JSM6100 , Jeol, Japan) was done to study the site of adherence of $E$. coli to spermatozoa and the effect of purified sperm ligand on spermatozoa. 
Processing of samples was done according to the method described by Hafez \& Kanagawa (1973) with slight modifications. For electron microscopy, sperm- E. colil sperm ligand agglutinates were mixed in $2.5 \%$ phosphate buffered glutaraldehyde and incubated at $37^{\circ} \mathrm{C}$ for 30 minutes. The mixture was then washed thrice with PBS and suspended in $0.5 \mathrm{ml}$ of PBS. One drop of fixed and washed sample was placed on a silver-painted adhesive tape and mounted on brass stub and air dried. $100 \AA$ thick gold coating was done and the specimen was observed.

\subsection{Results and Discussions}

Bacterial infections have long been recognized as having an association with infertility. It is also known that bacteria are capable of agglutinating and immobilizing spermatozoa. Antibiotic treatment of spermicidal bacteria in women, men, and the ejaculate itself has resolved the infections and resulted in pregnancies in many of the previously infertile couples. Occasionally, some infertility problems have not been associated with frank infections but have presented as subclinical asymptomatic prostatitis in males whose initial sperm motility diminished over a several hour time interval.

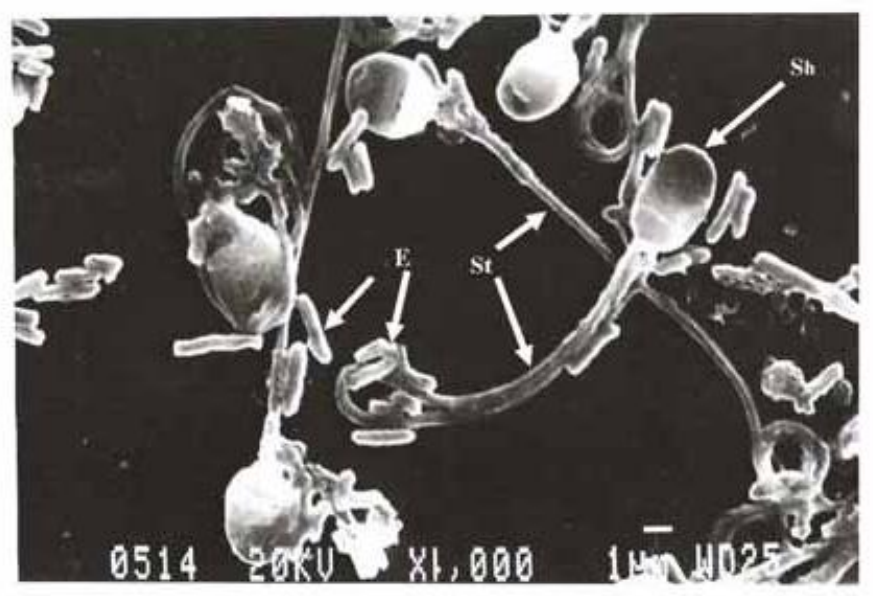

Figure 1. Scanning electron micrograph of Escherichia coli (E) adhered to both sperm heads (Sh) and tails (St) (at X 1000 magnification).

Bacteria affect sperm motility by adherence, agglutination and dialyzable factors. It is known that there is a significant negative effect of $E$. coli, Enterococci and coagulase negative Staphylococci towards sperm motility, morphology and viability (Esfandiari et al., 2002; Rodin et al., 2003, Sanack-Maciejewewska et al., 2005). Bacterial agglutination strong enough to induce hetero- agglutination of the microorganisms with motile sperm has been described for $E$. coli.

In the present study also $E$. coli isolated from asymptomatic males was shown to immobilize the spermatozoa. Sperm motility was inhibited by cell culture and washed cells but not by culture supernatant suggesting that agglutinating activity is associated with bacterial cells and not their metabolites.

Scanning electron microscopy showed close association between E. coli and sperm. Adherence of $E$. coli was seen on both the sperm head and tails (Fig.1). This observation is supported by the study made by Wolff et al. (1993) where they have reported the adherence of $E$. coli to both heads and tails of spermatozoa. However, Staphylococcus aureus was observed to adhere only to the tails of the spermatozoa and cause agglutination (Ohri \& Prabha, 2005).

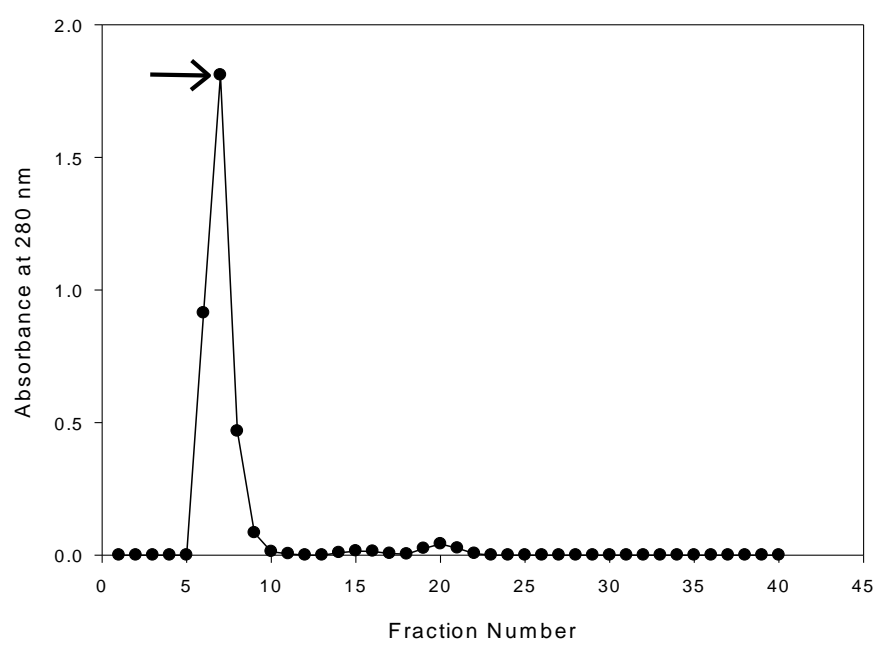

Figure 2. Column chromatographic pattern obtained after Sephadex G-200 gel filtration of dialyzed and filtered supernatant containing sperm ligand on $E$. coli, showing the presence of ligand in fractions 6-9 with peak value in fraction 7 (arrow refers to sperm ligand on E. coli). 
Pretreatment of $E$. coli by sonication produced bacterial fragments that were still able to agglutinate sperm. Centrifugation of $E$. coli fragments at $10,000 \mathrm{~g}$ for 5 minutes completely removed sperm agglutinating elements from the solution. Extraction of sonicated bacterial cells with $3 \mathrm{M} \mathrm{NaCl}$ released the ligand into the solution. Sperm ligand could also be extracted from washed $E$. coli cells without sonication by $3 \mathrm{M} \mathrm{NaCl}$. This method gave better yield of sperm ligand as compared to sonicated cells.

Therefore, for further studies sperm ligand was extracted from washed $E$. coli cells without sonication. Sequential chromatography procedure included dialysis, molecular weight sieve chromatography and ion exchange chromatography on DEAE cellulose column.

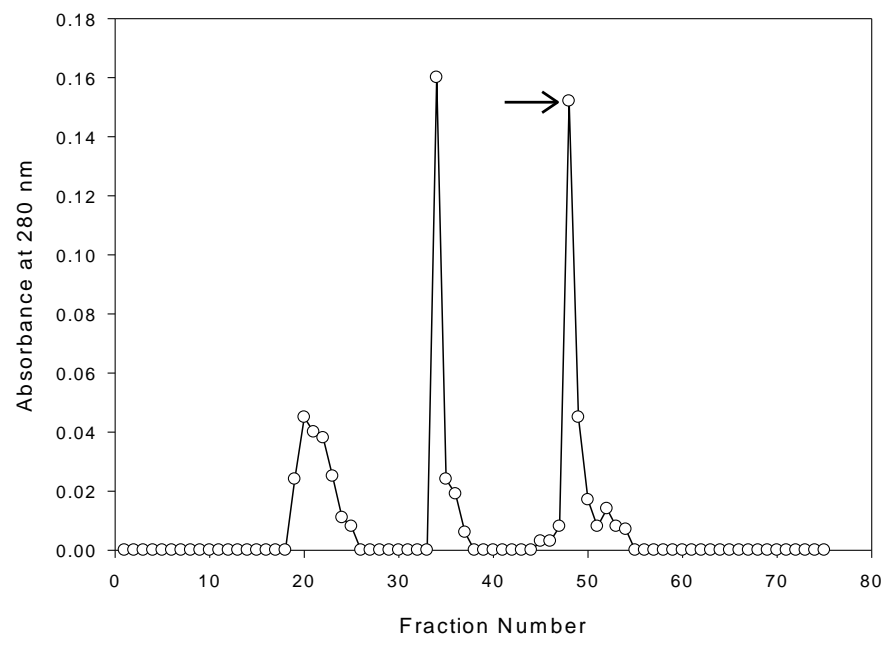

Figure 3. DEAE cellulose chromatography of G200 pooled and PEG concentrated fractions revealed the presence of three peaks but the agglutinating activity was present only in the fractions 46-49 with peak value in fraction 48 (arrow refers to sperm ligand on E. coli).

The column chromatographic pattern on Sephadex G-200 (Fig.2) showed that the agglutinating activity was present in the fractions 6-9 with a peak value in fraction 7 . The fractions showing agglutinating activity were pooled and concentrated using polyethylene glycol (PEG) and were applied to DEAE cellulose column. The sperm ligand could be eluted with PBS $(50 \mathrm{mM}$, $\mathrm{pH}$ 7.2) containing $0.4 \mathrm{M} \mathrm{NaCl}$ (Fig.3). The fractions showing agglutinating activity were 46-
49 with peak value in fraction 48 . With this procedure the ligand was purified with a $42 \%$ recovery. Its molecular weight was estimated at $\sim 71 \mathrm{KDa}$ by sodium dodecyl sulfatepolyacrylamide gel electrophoresis (Fig. 4). The ligand was found to be heat labile as it could not withstand a temperature of $60^{\circ} \mathrm{C}$ for 10 minutes, which is in contrast to spermatozoal immobilization factor isolated from $E$. coli by Paulson and Polakoski (1977), which was excreted in the medium and stable to heating, freezing and lyophilization.

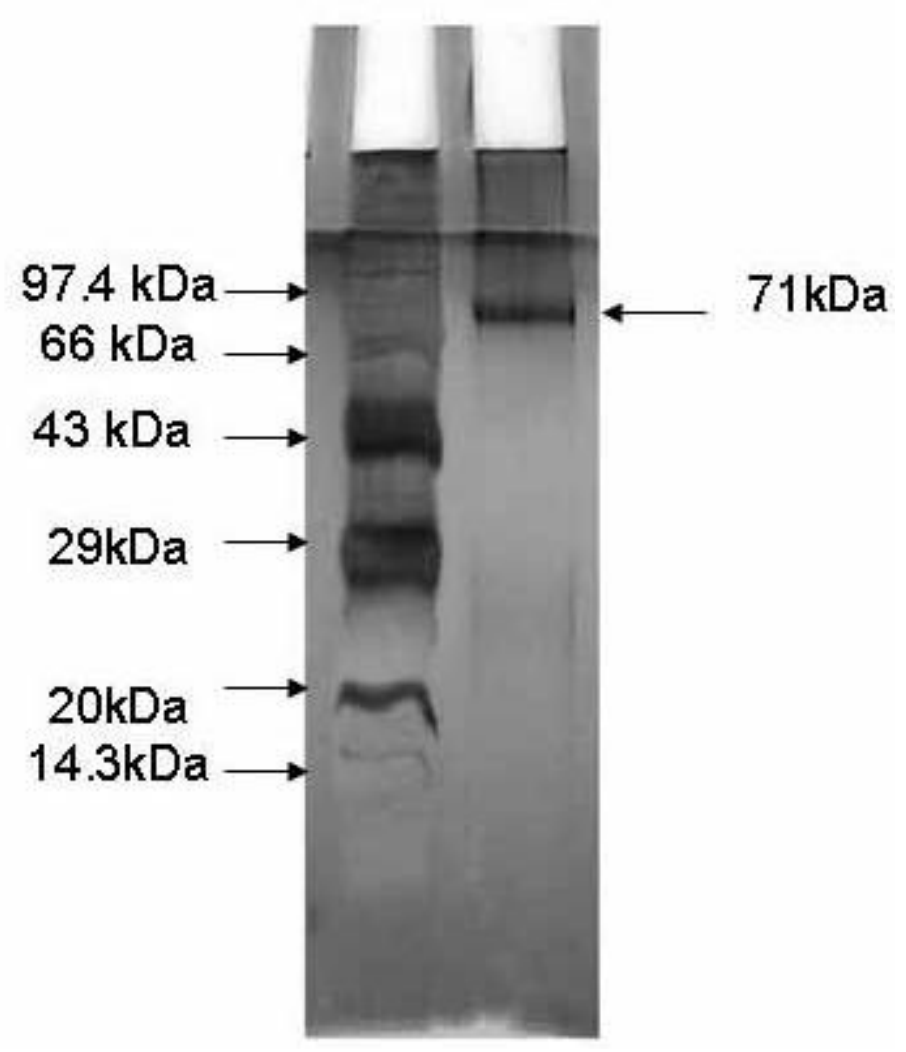

Figure 4. SDS-PAGE of purified sperm ligand, with Lane1 containing Standard protein marker and Lane2 containing DEAE cellulose purified and concentrated fraction. Molecular weight approx $71 \mathrm{kDa}$.

Minimum effective concentration of purified sperm ligand showing immediate agglutination of

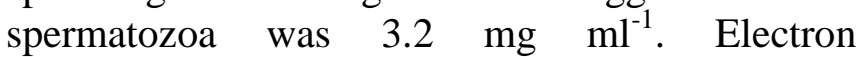
microscopy studies of washed sperm cells treated with purified sperm ligand showed profound morphological alterations on human spermatozoa 
including curling of tail (Fig.5), indicating that the morphological defects account for the immobilization of spermatozoa by the ligand. In a similar study Diemer et al. (2000) have reported the presence of multiple alterations on ultrastructure of spermatozoa upon artificial inoculation with $E$. coli, revealing the damage on sperm plasma membrane as well as the acrosome, thereby leading to immobilization.

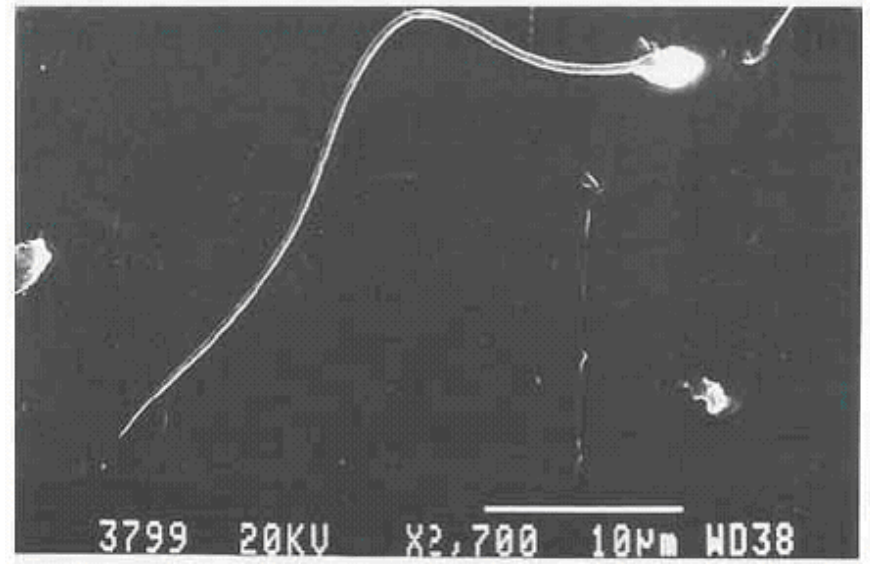

Figure 5a. Scanning electron micrograph of normal human spermatozoa (at $X \quad 2,700$ magnification), serving as control.

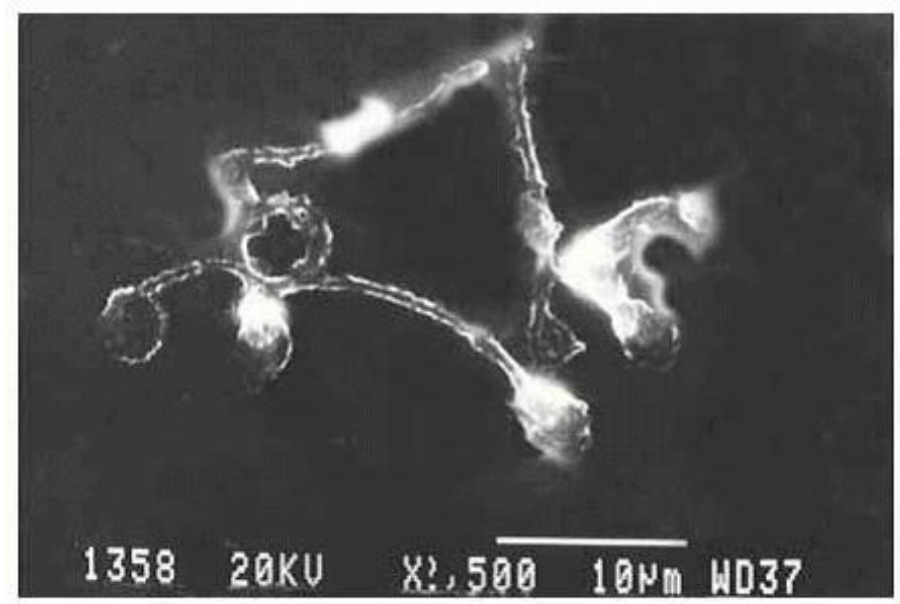

Figure 5b. Scanning electron micrograph of spermatozoa treated with purified sperm ligand (at X 2,500 magnification), showing the presence of morphological alterations on head, neck and curling of tail.
This study identifies a receptor- ligand interaction between $E$. coli and spermatozoa that results in sperm agglutination. Because the surface of spermatozoa is rich in glycoproteins, even asymptomatic colonization of male and female genitalia with bacteria may result in similar species specific interactions, causing agglutination of motile sperm.

\section{References}

1. Bartoov B, Ozbonfil D, Maayan MC, Ohad E \& Nitzan Y (1991) Virulence characteristics of male genital tract Escherichia coli isolated from semen of suspected infertile men. Andrologia 23: 387-394.

2. Bergey's Manual of Determinative Bacteriology (1994) Bergey DH \& Holt GJ. $9^{\text {th }}$ Edition. Lippincott Williams \& Wilkins, Baltimore, Maryland U.S.A.

3. Bonde JP, Ernst E, Jensen TK, Hjollund NH, Kolstad H, Henriksen TB, Scheike T, Giwercman A, Olsen J \& Skakkebaek NE (1998) Relation between semen quality and fertility: a population-based study of 430 firstpregnancy planners. Lancet 352: 1172-1177

4. Diemer T, Weidner W, Michelmann HW, Schiefer HG, Rovan E \& Mayer F (1996) Influence of Escherichia coli on motility parameters of human spermatozoa in vitro. Int J Androl 19: 271-277.

5. Diemer T, Huwe P, Michelmann HW, Mayer F, Schiefer HG \& Wiedner W (2000) Escherichia coli-induced alterations of human spermatozoa. An electron microscopy analysis. Int J Androl 23: 178-186.

6. Esfandiari N, Saleh RA, Abdoos M, Rouzrokh A \& Nazemian Z (2002) Positive bacterial culture of semen from infertile men with asymptomatic leukocytospermia. Int J Fertil Women's Med 47: 265-270.

7. Giamarellou H, Tympanidis K, Bitos NA, Leonidas E \& Diakos GK (1984) Infertility and chronic prostatitis. Andrologia 16: 417422.

8. Golshani M, Taheri S, Eslami G, Suleimani Rehber AA, Fallah F \& Goudarzi H (2006) Genital tract infection in asymptomatic 
infertile men and its effect on semen quality. Iranian J Publ Health 35: 81-84.

9. Hafez ESE \& Kanagawa H (1973) Scanning electron microscopy of human, monkey and rabbit spermatozoa. Fertil Steril 24: 776-787.

10. Hafez ESE (1980) Physiology of spermatozoal insemination in the female reproductive tract. In homologous artificial Insemination JC Emperiare, A Audebent, ESE Hafez (eds.) The Hague, Mastinus Nijhoff Publishers.

11. Huerta M, Cervera AR, Hernandez I \& Ayala AR (2002) Frequency and etiology of seminal infections in the study of infertile couples. Ginecol Obstet Mex 70: 90-94.

12. Huwe P, Diemer T, Ludwig M, Liu J, Schiefer HG \& Weidner W (1998) Influence of different uropathogenic microorganisms on human sperm motility parameters in an in vitro experiment. Andrologia 301: 55-59.

13. Karpuz V, Gokturk A \& Meral Koyuturk M (2007) The effects of sperm morphology and motility on the outcome of intracytoplasmic sperm injection. Marmara Med J 20: 92-97.

14. Khalili MB \& Sharifi-Yazdi MK (2001) The effect of bacterial infection on the quality of human's spermatozoa. Iranian J Publ Health 30: $119-122$.

15. Menkveld R, Wong WY, Lombard CJ, Wetzels AMM, Thomas CMJ, Merkus HMWM \& Steegers-Thuenissen RPM (2001) Semen parameters, including WHO and strict criteria morphology, in a fertile and subfertile population: an effort towards standardization of in-vivo thresholds. Hum Reprod 16: 11651171.
16. Ohri M \& Prabha V (2005) Isolation of sperm- agglutinating factor from Staphylococcus aureus isolated from a woman with unexplained infertility. Fertil Steril 84: 1539-1541.

17. Paulson JD \& Polakoski KL (1977) Isolation of a spermatozoal immobilization factor from Escherichia coli filtrates. Fertil Steril 28: 182185.

18. Pellati D, Mylonakis I, Bertoloni G, Fiore C, Andrisani A, Ambrosini G \& Armanini D (2008) Genital tract infections and infertility. Eur J Obstet Gynecol Reprod Biol Available from

http://www.ncbi.nlm.nih.gov/pubmed/18456385

19. Rodin DM, Larone D \& Goldstein M (2003) Relationship between semen cultures, leukospermia, and semen analysis in men undergoing fertility evaluation. Fertil Steril 3: 1555-1558.

20. Sanack-Maciejewska D, Ciupinska M \& Kurpisz M (2005) Bacterial infection and semen quality. J Reprod Immunol 67: 51-56.

21. Wolff H, Panhans A, Stolz W \& Meurer M (1993) Adherence of Escherichia coli to sperm: a mannose mediated phenomenon leading to agglutination of sperm and Escherichia coli. Fertil Steril 60: 154-158.

22. World Health Organisation (1999) WHO laboratory manual for the examination of human semen and semen cervical mucus interaction. $4^{\text {th }}$ ed. Cambridge University Inc, Cambridge, UK, pp.: 1-138. 